\title{
Canadian technology budget downgrades basic science
}

Montreal. A new budget announced last week by Canada's Finance Minister, Paul Martin, has produced plans for a mechanism to help companies compete internationally in high-technology industries.

But the proposals seem certain to confirm the fears of many basic scientists that they are not among the Liberal government's priorities, thus further eroding what researchers see as the basis of the country's technological advances.

Furthermore, the new approach, called Technology Partnerships Canada (TPC), will involve no additional money, but will rely on loans using funds reallocated from existing government programmes.

The budget also includes a cut of more than 10 per cent in federal financing for Atomic Energy of Canada Limited. This will mean dropping all research not connected to the Candu nuclear reactor, including projects such as the neutron-scattering laboratory, nuclear fusion work and support for the Sudbury Neutrino Observatory.

TPC forms the centrepiece of Canada's long-awaited science and technology strategy, Science and Technology for the New Century (see Nature 377, 665; 1995). First promised early last year, the strategy is the outcome of nationwide consultations and focuses in particular on the need to develop partnerships between the private sector, academic institutions and other governments.

The strategy will involve what the government calls "a new system of governance". This will include the creation of a Science and Technology Advisory Council to advise the prime minister and cabinet, and the requirement that all federal departments and agencies report annually to parliament on their expenditures, activities and priorities in science and technology.

Despite the apparent logic of such moves - which are broadly similar, for example, to those introduced by the British government three years ago - some sceptics are already pointing out that the advice of federal advisers and advisory bodies on science and technology in Canada is often ignored.

It is not long, for example, since a body set up by the federal government to provide it with advice on science policy - the Science Council of Canada - was abolished, and the recommendations of the prime minister's National Advisory Board of Science and Technology were rejected.

The TPC will involve what the government calls "investments" amounting to C $\$ 250$ million (US\$183 million) a year by 1998-99 that will be fully repayable. The government will share with the private sector both risks and rewards: money from the fund will be repaid from royalties generated by successful projects, and will be recycled back into the fund for future investments.

Potential partners in TPC will be "wellmanaged, financially-sound incorporated businesses that can demonstrate their ability to successfully complete their project", says Industry Canada, the government agency responsible for the programme. These can include groups or alliances, associations or consortia from all regions of Canada.

Government officials say that although Canada has a strong tradition of achievements in fields such as telecommunications, medicine and software, its overall performance lags behind that of its international competitors. This has contributed over the

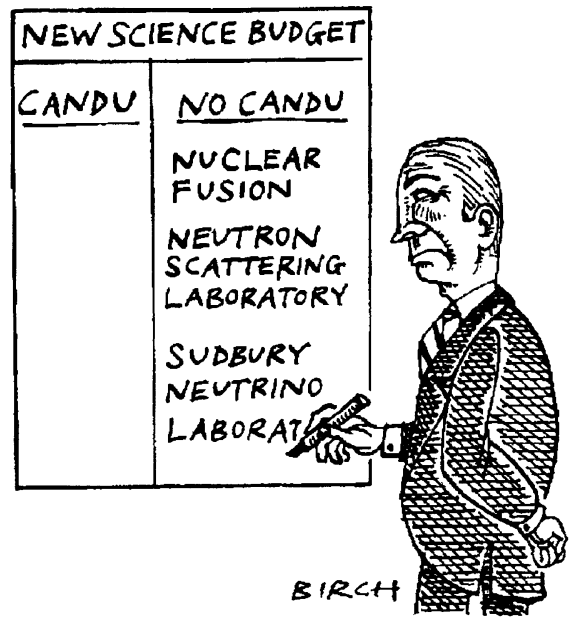

past two decades to weak productivity, suboptimal employment growth and large government deficits.

The fund's focus will be on environmental technologies, on what are called "enabling technologies" such as biotechnology, information and advanced manufacturing technologies that make industries more efficient and productive, and on the aerospace and defence industries, including "defence conversion".

Facilities slated for closure in three months time under the AECL budget cuts include the neutron-scattering laboratory at Chalk River. Materials testing methods developed there demonstrated the integrity of the sealant ring that was redesigned after a similar one led to the explosion on the space shuttle Challenger in 1986.

Federal support for fusion research, which is overseen by AECL, will also cease in a year's time. The director of the Canadian Centre for Magnetic Fusion in Varennes, Quebec, which operates the fusion reactor, says he expects this will mean the end of its programme, although he plans to fight the cuts. The Canadian Fusion Fuels Technology Project in Toronto is also expected to close.
Courts back research and compensation for Japanese HIV victims

Tokyo. A legal battle between HIV-positive haemophiliacs and five companies that distributed contaminated blood products moved closer to resolution last week, when the Osaka and Tokyo district courts released a new compromise proposal, a revised form of a compromise suggested last October (see Nature 377, 467; 1995).

In addition to financial compensation, the courts recommend that the government should set up a medical institution to provide treatment to AIDS and HIV-positive patients, to carry out research into AIDS and to provide education to other hospitals about AIDS and treatments for HIV.

The new plan recommends that, in addition to the $¥ 45$ million (US\$430,000) compensation for each plaintiff recommended in the initial compromise, the defendants should also set up a system for providing medical treatment and financial assistance to the victims. This proposal is probably the last to be offered by the courts, and is widely expected to bring the six-anda-half year-old court case to a conclusion.

The courts' proposal confirms that the defendants are responsible for the disaster, in which an estimated two-fifths of Japan's 5,000 haemophiliacs were infected with HIV. It recommends that they pay $¥ 150,000$ a month to each patient who has subsequently developed AIDS.

Testu Noma, the counsel for the plaintiffs in the Tokyo court case, says the proposal does not meet all the group's demands for compensation. But he is optimistic that an agreement can be reached, provided that the companies can be persuaded to apologize.

Japan's new minister for health, Naoto Kan, recently apologized to the victims and admitted the government's responsibility for its role in the continued use of blood products which had not been heat-treated to kill HIV and other viruses (see Nature $379,663 ; 1996)$. But the five companies that distributed the contaminated blood products have remained reluctant to admit negligence.

Two foreign-based companies in particular - Baxter Ltd and Bayer Yakuhin Ltd have been loath to make admissions of guilt, possibly because such admissions might be used against them in other countries where the companies operate.

The plaintiffs plan to visit the offices of each of the five companies this week to receive apologies before the deadline for the compromise proposal expires at the end of this month. If no agreement is reached by then, says Noma, the matter will revert to the courts, and justice, he says, may be delayed indefinitely. Stephen Barker 